\title{
Factors influencing smoking among secondary school pupils in Ilala Municipality Dar es Salaam March 2007
}

\author{
By: Sadru Green (B.Sc. EHS3 - 2006/2007)
}

\begin{abstract}
\section{INTRODUCTION}

Tobacco epidemic is described as a global crisis, it is one of the two major causes of death and still growing, the other one being HIV/AIDS. The number of smokers worldwide is estimated to be 1.3 billion people, $84 \%$ of these smokers live in developing countries. Cigarette smoking, consumption of other tobacco products and passive smoking are the world leading preventable causes responsible for about 5 million deaths a year, mostly in poor countries and poor populations. Young adults most of which are in secondary schools are at a higher risk of contracting problems caused by tobacco use; this is due in part to inadequate knowledge about health effects caused by tobacco use and also there is a lot of material in the media that glorify smoking. In Tanzania especially Dar-es-Salaam, there is reported a 1.6\% prevalence rate amongst secondary school pupils.
\end{abstract}

\section{OBJECTIVE}

To determine the socio-environmental factors that may influence smoking amongst secondary school pupils in Ilala municipality in Dar-es-Salaam.

\begin{abstract}
METHODOLOGY
This was a cross sectional descriptive study that involved 260 respondents selected randomly from five randomly selected secondary schools. A Swahili structured close ended questionnaire were used in data collection and the study was carried in between March and April, 2007. Data coding was done during data entry \& quantitative data analysis was done through SPSS Version 12.0, a computer package programme, whereas qualitative data sociological/anthropological methods in data analysis were used.
\end{abstract}

\begin{abstract}
RESULTS
The results revealed that $14.2 \%$ of the pupils reported to have ever smoked and the range of age to smoke the first cigarette were between 6 to 20 years with a mean age of $17 y e a r s . ~ A b o u t ~ 2 \%$ were current smokers. Most of the pupils (88\%) declared smoking as not normal for young people, owing to the harmful effects that are contributed by cigarette smoking. About $80 \%$ of the pupils mentioned that smoking is addictive. However half of the pupils reported that for one who has started to smoke it is not easy to quit any time one desires to quit. The factors that were found to contribute for their experiment to smoke include peer influence, family influence and the school environment, advertisement and promotion and bad beliefs associated with smoking behaviour.
\end{abstract}

\section{CONCLUSION AND RECOMMENDATION}

Substantial proportions of pupils have tried or have experimented smoking. Peer influence seems to be a major influencing factor for taking up or experimenting smoking. Schools can be a good environment for taking or experimenting smoking.

More analytical work on a large scale is needed to determine the extent to which environmental factors influence smoking among pupils.

A study is needed to investigate whether cigarette advertising has any impact in the brand choosing among young smokers in a Tanzania society.

\section{INTRODUCTION}

Tobacco epidemic is described as a global crisis, it is one of the two major causes of death and still growing, the other one being HIV/AIDS'. Cigarette smoking, consumption of other tobacco products and passive smoking are the world leading preventable cause responsible for about 5 million deaths a year, mostly in poor countries and poor populations ${ }^{1}$. The number of smokers worldwide is estimated to be 1.3 billion people, $84 \%$ of these smokers live in developing countries ${ }^{1}$. In these countries an increase in number of smokers is a result of low levels of awareness of the health risks associated with tobacco use, compounded by the long time lag between the cause and effects of tobacco use as well as by aggressive tobacco industry 
advertising using free market policies ${ }^{2}$. It is estimated that the number of children and young people taking up smoke everyday is between 68,000 and 84,000 for low and middle income countries around the world ${ }^{3}$. In Sub-Saharan Africa, the prevalence of smokers is $6 \%$ and it is said to be lower as compared to other region ${ }^{3}$ though snuff and chewer of tobacco at higher rate than the manufactured cigarettes ${ }^{4}$. In Tanzania especially Dar-es-Salaam, reported a 1.6\% prevalence rate amongst secondary school pupils. ${ }^{5}$. Young adults most of which are in secondary schools are at a higher risk of contracting problems caused by tobacco use; this is due in part to inadequate knowledge about health effects caused by tobacco use \& also there is a lot of material in the media that glorify smoking. This comes as advertisements, films and cigarette promotion activities further more have peers or role models who smoke which further expose them to smoking behaviour'mob psychology'. Identification of socio-economic factors that influence tobacco smoking among secondary school pupils helps in deciding proper ways to control smoking habit and hence control health effects resulted by smoke use among these future leaders. This study aimed at ascertaining the socio economic factors that influence smoking among secondary schools in Tanzania.

The burden due to smoking is heavy especially in developing countries. The families of smokers suffer from ill health, inability to bare costs of health care and premature death. Studies done by Adult Morbidity and Mortality Project (AMMP) in Tanzania have shown smoking to be a significant risk factor of death among persons ageing 15years and above in Kilimanjaro region ${ }^{6}$.

\section{METHODOLOGY}

A descriptive cross-sectional study was conducted in five secondary schools from March to April in 2007 in Ilala Municipality aiming to retrieve socioenvironmental factors that influence smoking amongst secondary school pupils.

The schools were randomly selected by writing the school names on a piece of paper, the papers shuffled and an individual was asked to pick up the five pieces of paper corresponding to five schools. In each school 52 pupils were interviewed, hence a total of 260 secondary school pupils were involved in the study. The pupils were randomly picked from the pupils' registers using table of random numbers. Selected pupils were then called for the interview and those who were not available at the time were followed up another day. A Swahili structured close ended questionnaire was used in data collection from pupils. Data coding was done during data entry, and data analysis was done after the completion of all data entry by using SPSS 12.0 Computer software. Ethical clearance was obtained from MUCHS ethical committee. The Ministry of Education and Vocational Training, Local Government in Ilala municipal council and concerned schools gave their consent before the study could be affected. Finally the pupils who were selected to join the study were requested to give their own consent.

\section{RESULTS}

Table 1: History of smoking by sex

\begin{tabular}{|l|l|l|l|}
\hline History of smoking & Male & Female & Total \\
\hline Yes & $24(16.8 \%)$ & $12(10.8 \%)$ & $36(13.8 \%)$ \\
No & $125(83.2)$ & $99(89.2 \%)$ & $223(86.2 \%)$ \\
\hline Total & $149(100 \%)$ & $111(100 \%)$ & $260(100 \%)$ \\
\hline
\end{tabular}

A higher proportion of males (16.8\%) and (10.8\%) of the females reported to had ever smoked at least once. There was no significance difference in smoking between males and females. Among the pupils who had ever smoked, $17(47.2 \%)$ reported to had started smoking between the age of $11-15$ years; $50 \%$ of the male and $41.7 \%$ of the female pupils reported to get their first cigarette when they were with their friends.

Among the ever smokers, $\mathbf{1 3 . 9 \%}$ of those who had ever smoked responded to continue smoking. The prevalence of cigarette smoking was $\mathbf{1 . 9 \%}$ of all pupils studied. 
Table 2: Frequency of pupils with role models smoking pattern $(\mathrm{N}=\mathbf{2 6 0})$

\begin{tabular}{|c|c|c|}
\hline Role model & Frequency & Percentage (\%) \\
\hline \multicolumn{3}{|l|}{ Father } \\
\hline Yes & 38 & 14.6 \\
\hline No & 222 & 85.4 \\
\hline \multicolumn{3}{|l|}{ Mother } \\
\hline Yes & 3 & 1.2 \\
\hline No & 257 & 98.8 \\
\hline \multicolumn{3}{|l|}{ Brother } \\
\hline Yes & 30 & 11.5 \\
\hline No & 230 & 88.5 \\
\hline \multicolumn{3}{|l|}{ Sister } \\
\hline Yes & 2 & 0.8 \\
\hline No & 258 & 99.2 \\
\hline \multicolumn{3}{|c|}{ Religious leaders } \\
\hline Yes & 12 & 4.6 \\
\hline No & 248 & 95.4 \\
\hline \multicolumn{3}{|c|}{ Closest friend } \\
\hline Yes & 62 & 23.8 \\
\hline No & 198 & 76.2 \\
\hline \multicolumn{3}{|l|}{ Classmates } \\
\hline Yes & 22 & 8.5 \\
\hline No & 238 & 91.5 \\
\hline \multicolumn{3}{|l|}{ Teachers } \\
\hline Yes & 34 & 13.1 \\
\hline No & 226 & 86.9 \\
\hline
\end{tabular}

Out of 260 pupils, 91 (35\%) pupils reported to have members who smoke at their households. The immediate role models influencing pupils to smoke were fathers, mothers, brothers and sisters. The highest proportion of the pupils (14.6\%) had fathers who smoked in their immediate environment.

In the school environment, $13.1 \%$ of the studied pupils had teachers who smoked.

Table 3: Perception as normal to smoke for young people by history of smoking

\begin{tabular}{|l|l|l|l|}
\hline \multirow{2}{*}{$\begin{array}{l}\text { Smoking is perceived as } \\
\text { normal practice }\end{array}$} & \multicolumn{2}{|l|}{ History of smoking } & \multirow{2}{*}{ Total } \\
\cline { 2 - 3 } & Yes & No & \\
\hline Yes & $11(34.4 \%)$ & $21(65.6 \%)$ & $32(100 \%)$ \\
No & $25(11.0 \%)$ & $203(89.0 \%)$ & $228(100 \%)$ \\
\hline Total & $36(13.8 \%)$ & $224(86.2)$ & $260(100 \%)$ \\
\hline
\end{tabular}

87.7\% of the sampled pupils responded smoking as not normal, the relationship between smoking and perception as normal practice, $34.4 \%$ of the pupils who perceived as normal for a young person to smoke had ever smoked likewise $11 \%$ of those who reported as not normal had ever smoked as well. 


\section{Table 4: Effects attributed by cigarette smoking}

\begin{tabular}{|l|l|l|}
\hline Effects & Frequency & Percent \\
\hline Respiratory problems & 109 & 41.9 \\
Cancers & 134 & 51.5 \\
Teeth discoloration & 8 & 3.1 \\
Others & 9 & 3.5 \\
\hline Total & 260 & 100 \\
\hline
\end{tabular}

It was also reported by $81.5 \%$ of the pupils that their community believed that smoking was harmful and the mentioned ailments attributed by cigarette smoking were cancers (51.5\%) and respiratory problems (41.9\%).

\section{Perception of pupils to health lifestyles related to smoking}

This was aimed to cover the perception of pupils to health in relation to smoking. The pupils were asked whether smoking is addictive. Most of the pupils (80.4\%) considered that smoking is addictive.

The majority (84.2\%) reported to have ever read the warning messages on the cigarette pack. Out of those who had ever read the warning messages, 77.6\% reported that the message was applied to all smokers. The perception of pupils on whether they can smoke and quit as they liked. The response was that almost half (49.2\%) of the pupils responded that they can smoke and quit as they like. The other half saw that is not easy to quit smoking when one has started smoking.

Upon asking the pupils on the acceptable number of cigarette that one should smoke, over $96 \%$ responded that no one should smoke.

\section{DISCUSSION}

The findings from this study shows smoking status of the young people represented by the pupils from secondary schools. It involved pupils from form three to form six whose age ranged from 14 to 25 years old with the mean age of 17 years. The sampled pupils were 260 with 149 (57.3\%) males and 111 (42.7\%) females from five secondary schools in Ilala Municipality in Dar-es-Salaam.

Amongst secondary school pupils in Dar-es-Salaam $1.6 \%$ were established smokers (Mbatia, 1996). In these studies the age of onset was between 5-15years. The major influencing factors were identified to the peer pressure and parental smoking. Smoking initiation at an early age has also been shown to be the case in Tanzania where a large percentage of young people have an experience with drugs or substances like tobacco and alcohol at around 10years ${ }^{1,5,8}$.

The prevalence of current smokers in this study among the sampled population in Ilala Dar es Salaam was $1.9 \%$, resembling to that done by Mbatia in Dar es Salaam in 1996. The average percent of pupils who had ever smoked was $14.2 \%$ and most of the pupils reported to start smoking at the age of 11-15years and the range was between 6 to 20 years of age. The percentage of student who continued to smoke was $1.9 \%$, however among the ever smokers, only $13.8 \%$ responded to continue smoking. The theory of social learning 9 places an individual in a social context and explains that young people acquisition of behaviour is based on a web of interpersonal and social relationship in which an individual is placed. The immediate environment for the young comprises of their best friends, parents and siblings, then followed by the peers, relatives, and teachers and further away the societal leaders, media and community policies ${ }^{10}$. When these seen smoking then a young person can imitate the action. The immediate role models of the pupils whom were found to influence pupils to smoke were father, mother, brother and sister. It is possible that young people who have parents who smoke may perceive smoking as acceptable and may not get parental sanctions for smoking. Among the pupils studied, $14.6 \%$ had fathers who smoked followed by brothers by $11.2 \%$. This shows that many pupils had their father and brother who smoked from whom they were likely to have been observed and hence adopted on the behaviour of smoking. In the study done by Richardson et al, $2002^{11}$ found that there is a link between the connectedness of the family structure and smoking in young people. Apart from the immediate role models, closest friend smoking was associated with the student to have ever smoked There was an association between smoking and whether it was regarded as normal for the young person to smoke (Chi square $=12.892, \mathrm{P}<0.05)$. The 
practice of cigarette smoking in the community has contribution to influence young people to engage in smoking. Most of the pupils reported that it was not normal in their community for young people to smoke. About 88\% responded as not normal for young people to smoke. The reasons that were presented included the harmful effects that are contributed by cigarette smoking. The effects like cancer and respiratory problems were found to be largely believed to have health effects. Teeth discoloration was another harmful effect reported to be caused by smoking cigarette.

\section{CONCLUSIONS}

Substantial proportions of pupils have tried or have experimented with smoking. These had been so due to various factors such as the peer influence, family influence, the school environment, cigarette advertisement and promotion.

Student, their teachers and the community as a whole need to be properly informed on harmful effects associated with smoking.

Peer influence seems to be a major influencing factor for taking up or experimenting with smoking. Schools environments have a supporting condition for the pupils to smoke or to experiment the use of tobacco products and hence the means to curb the problem is by making them aware.

\section{RECOMMENDATIONS}

More analytical work on a large scale is needed to determine the extent to which environmental factors influence smoking among pupils.

There should be emphasis by all stakeholders on the avoidance of smoking in Public places stop the Environmental Tobacco Smoke (ETS) which has effect to the children and women who are at higher risk.

The interventions programmes should consider the influencing factors such as peer, exposure to advertisements and promotion.

\section{ACKNOWLEDGEMENT}

I would like to express my sincere gratitude to my supervisor Mr. C.K.Makwaya from the Department of
Epidemiology \& Statistics for providing invaluable advice and guidance in doing this study. Furthermore I would like to thank the Administration of Dar es Salaam City and Ilala Municipality for their permission in order to conduct the research to their areas of jurisdiction. Thanks go to the Heads of secondary schools who kindly welcomed me and allowed for the conduction of research in their area of jurisdiction and the pupils for participation.

\section{REFFERENCES}

1. World Health Organization Report (2003). Neglected Global Epidemic Tobacco Control; Strengthening National Effort, Chapter 6, pg 91-95

2. World Bank Group (2004). Framework Convention on Tobacco Control

3. Chaolupka, Jha P (2003), Tobacco Control in Developing Countries: Oxford University Paper for World Bank.

4. Saloojee $Y$ (2000), Regional Summary for the African Region. Tobacco Control Country Profiles, American Cancer Society

5. Mbatia J (1996). Tobacco the Silent Killer: Mental health Association of Tanzania Publications.

6. Ministry of Education and Culture, Tanzania (2003). Tanzania Education Directory,

7. WHO KAP SURVEY (2002). Substance Abuse in Tanzania: Study in Kinondoni District Dar es Salaam and Old Store Town Zanzibar

8. Mokiti F (1996). Prevalence of Cigarette Smoking among Adolescents in Arusha Municipality: Proceedings for TPHA $18^{\text {th }}$ Annual Conference;

9. Bandura A, (1977). Social Learning Theory: Engelwood Cliffs, NJ: Prentice Hall.

10. Perry CL (1999). Creating Health Behavior Change: How to Develop Wide Programs for Youth SAGE Publications Inc Thousand Oaks

11. Lloyd-Richardson E.E, Papandolanos G, Kazura A, Stanton C, Niaura R (2002), Differentiating Stages of Smoking Intensity among Adolescents: Stage Specific Psychological and Social Influences. Journal of Consulting and Clinical Psychology; 70(4): 998-1009 